\title{
Aproximaciones al fenómeno de la transposición semiótica: lenguajes, dispositivos y géneros
}

\author{
Nicolás Diego BERMÚDEZ \\ (Universidad de Buenos Aires, \\ Argentina)
}

RESUMO: El objeto de este trabajo es reconsiderar algunas cuestiones ligadas al fenómeno de la transposición, deteniéndonos especialmente en una de las variantes más transitadas en la cultura contemporánea: el pasaje de una obra literaria al cine. Dos dimensiones nos interesa destacar: la dimensión material (el dispositivo) y las determinaciones genéricas.

PALAVRAS-CHAVE: transposición; dispositivo; género; estilo

\begin{abstract}
The aim of this work is to consider some problems related to transposition phenomenon, especially tackling one of his more studied variants in the contemporary culture: the passage from a literary work to cinema. Two aspects of transposition we want to emphasize: the material aspect (the device) and the generic determinations.
\end{abstract}

KEYWORDS: transposition; device; genre; style 


\section{INTRODUCCIÓN}

Nuestro objetivo es reflexionar sobre algunas cuestiones que caracterizan al fenómeno transpositivo; especialmente, a la transposición de una obra literaria al cine. Para eso, haremos el siguiente recorrido: nos referiremos primero a la dinámica de las relaciones entre las organizaciones semióticas y la producción de sentido, luego al papel que allí tienen el dispositivo, los géneros y, finalmente, el estilo de época.

\section{LA TRANSPOSICIÓN COMO RASGO DE LA CULTURA CONTEMPORÁNEA}

Se podría definir a la transposición semiótica como la operación social por el cual una obra o un género cambian de soporte y/o de sistema de signos ${ }^{1}$. Como acostumbra acontecer, aparece como una definición demasiado sencilla en relación a la complejidad del fenómeno que describe. Incentivada por la aparición de las artes del espectáculo que intensificaron, gracias a sus materias significantes (luces, sonidos, disposición espacial de los cuerpos), la impresión de realidad en las artes miméticas, la transposición hacia instancias representativas que aseguren una mayor plenitud (por ejemplo: literatura a cine) se ha vuelto - sin duda - la operación socio-semiótica que define zonas claves de la cultura contemporánea. Consecuencia entonces del deseo de totalidad representativa de nuestra cultura, el fenómeno de la transposición aún no ha logrado, sin embargo, la atención que merece dentro de las reflexiones sobre la discursividad social. Aún hoy en Argentina al menos - no hemos ido mucho más allá de los primeros lineamientos generales que establecieron autores como Steimberg (1998) y Traversa (1986).

Sin embargo, tal ganancia semiótica puede ser valorada como una pérdida artística. Los apocalípticos, fieles al sentido lineal que le dan a la historia de la cultura, leen (o solían leer) la transposición de una obra literaria en soporte libro a los medios masivos en clave de pérdida: algo les están arrebatando. Como bien observa Steimberg (1998:96), esta jerarquización se confirma en la ausencia de crítica cuando el pasaje invierte su dirección (situación - claro está - mucho menos frecuente) ¿alguien osaría criticar, en términos de su fidelidad representativa, el trabajo sobre los relatos cinematográficos en - por ejemplo - El beso de la mujer araña de Manuel Puig? Steimberg ofrece varias razones para explicar este malestar (1998:97). Primero, la persistencia en el tiempo de una concepción ingenua del lenguaje verbal según la cual este no construye la realidad, sino que la transparenta - una especie de falta de reflexión (teórica) sobre la reflexividad (lingüística). Segundo: la sensación - no menos ingenua de que las artes que trabajan con la hibridación de lenguajes tienden a limitar el imaginario individual imponiéndole uno colectivo: el dispositivo de la ópera, del cine o de la historieta lleva inscripto en sus reglas y hábitos de uso un imaginario regional y/o de época. Así las cosas, invadido por imágenes que no son las suyas, el lector de literatura tenderá a confirmar, en la retórica de los lenguajes combinados, un empobrecimiento del caudal de sentidos posibles en relación al que ofrece la lectura de libros.

Si dejamos de lado una lectura negativa del fenómeno transpositivo, además de afirmar su protagonismo en la cultura contemporánea, conviene resaltar el hecho de que plantea una forma específica de producción de sentido. Todo pasaje implica una resignificación de la obra transpuesta, resignificación determinada tanto por factores 
semiológicos y materiales de carácter forzoso (llevar una obra literaria al cine, por ejemplo, implica un cambio de lenguaje y de dispositivo), como por otros eventuales, que aparecen cuando la posible operación transpositiva se demora en el tiempo o se aleja en el espacio y es entonces modulada por los intereses y representaciones de un nuevo presente y/u otra cultura (por ejemplo ¿cuáles elementos desaparecerían y cuáles se acentuarían en una nueva adaptación cinematográfica de Madame Bovary? ¿y qué acontecería en el caso de que se tratara de una producción de origen chino?). Detengámonos aquí para examinar en detalle cada una de estos factores.

\section{APROXIMACIONES AL ASPECTO SEMIOLÓGICO DE LA CUESTIÓN: De Benveniste a PeirCe}

El conjunto de problemas semiológicos que ofrece la transposición requiere - una vez más - volver a Benveniste, puesto que fue él quien abordó uno de los aspectos fundamentales de la cuestión: el de la no equivalencia sígnica. Benveniste (2002) dice recordemos - que no todos los sistemas significantes tienen como unidades a los signos, es decir, a entidades con significancia autónoma de los enlaces que puedan establecer, como sucede con los signos lingüísticos. Una escala musical, por ejemplo, está integrada por una articulación específica de unidades no significantes. En las artes plásticas se puede observar otra variable posible: hay significados, sí, pero no remiten a nada de manera unívoca, adquieren significación dentro del sistema que crea el autor; al contrario de lo que sucede con la lengua, el vínculo significante no es aquí una convención compartida más o menos idénticamente por todos los usuarios. Un dato es importante en este punto: la lengua es un sistema semiológico privilegiado; su conocimiento permite la comunicación, la cultura, la sociedad.

Esta no equivalencia de las unidades produce la no equivalencia de los vínculos entre sistemas. Benveniste reconoce tres tipos de relaciones:

De engendramiento: tiene lugar entre dos sistemas distintos aunque de igual naturaleza, el segundo de los cuales está construido a partir del primero y ejerce, en sincronía con este, una función específica (i.e. el alfabeto normal engendra el alfabeto Braille).

De homología: aparece cuando se instaura una correlación entre las partes de dos sistemas semióticos; la naturaleza de la conexión es variable; puede ser de orden conceptual (i.e. la que estableció Panofsky entre arquitectura gótica y pensamiento escolástico) o de orden poético (i.e. perfumes, colores y sonidos se corresponden en el universo literario de Baudelaire), puede establecerse por intuición o a través del razonamiento, puede ser estructural o sustancial.

De interpretancia: es la relación que especifica a la lengua y le otorga su preeminencia sobre los otros sistemas. A diferencia de éstos que deben ser articulados por un sistema distinto a ellos mismos (por ejemplo, valiéndose sólo de luces rojas, amarillas y verdes es imposible explicar las significaciones y el funcionamiento del semáforo ${ }^{2}$ ), la lengua se basta a sí misma para articularse (por ejemplo, la frase que acabamos de producir). Es el sistema interpretante de todos los otros sistemas semióticos, incluso de ella misma. 
La lengua se presenta así como la matriz en la que están comprendidas las otras organizaciones semióticas, y eso a causa de una forma de significar que le pertenece con exclusividad, la que Benveniste (2002:67) denomina la doble significación. Por un lado, tiene un modo semiótico de significación, que es el inherente al sistema y constituye, a partir de un principio diferencial, sus unidades: los signos; por otro lado, tiene también la lengua significación semántica, la que se produce con la puesta en uso del sistema lingüístico, es decir, con el discurso. Los otros sistemas carecen de tal bidimensionalidad: o bien tienen significación semiótica y no semántica (i.e. los mudras) o bien semántica sin semiótica (i.e. las expresiones artísticas).

Christian Metz (1975) adhirió a estas tesis al analizar el fenómeno cinematográfico, pues estudió la transposición indicando que el pasaje de un código a otro, de lo lingüístico a lo audiovisual, transcurre a nivel del significado a través de la actividad mediadora de la lengua (a la que llamó "comentadora universal"). A diferencia de la traducción, que es una operación de transcodaje de complejidad menor - se trata de organizaciones semióticas de naturaleza similar - la transposición pone en movimiento una múltiple interacción entre sistemas. Así, siempre existe, en el caso de la transposición al cine de una obra literaria, una equivalencia inestable: un sistema de signos se comparte (la lengua), otros no (los signos visuales).

Notemos aquí, como lo hace Benveniste, que esta concepción del sistema lingüístico va a estar ausente en el marco semiótico peirceano. En este, ni la lengua ni ninguna otra organización sígnica ocupan un lugar especial. No hay exterioridad ni funcionamiento diferencial en la semiosis de Peirce, ya que un signo sólo puede serlo de otro. Dice Benveniste:

Para que la noción de signo no quede abolida en esta multiplicación al infinito, es preciso que en algún sitio admita el universo una diferencia entre el signo y lo significado. Hace falta, pues, que todo signo sea tomado y comprendido en un sistema de signos. Ahí está la condición de la significancia. Se seguirá, contra Peirce, que todos los signos no pueden funcionar idénticamente ni participar en un sistema único (2002:49).

Entonces: la lengua aquí no es, como en el paradigma saussureano, el más acabado de los sistemas frente al cual deben medirse los otros, sino un conjunto de palabras al que ni siquiera se le reserva el privilegio de estar comprendido en una categoría diferencial; casi todas las palabras son símbolos, algunas, como los demostrativos, son indicios.

Nada impide, no obstante, pensar el fenómeno de la transposición desde la semiosis descrita por Peirce. Recordemos que, para este, tan pronto como un signo, en su devenir temporal, alcanza el nivel del interpretante, se encuentra listo para convertirse en la superficie en donde se asienta un nuevo signo, continuando, de esta manera, un proceso que es teóricamente ilimitado: la semiosis ad infinitum. El interpretante no es necesariamente un ser humano, tampoco un agente determinado: es una función. Puede ser el resultado, el alcance, la consecuencia, la repercusión, el destinatario, el dativo del trabajo de semiosis operado en el interior de un signo (Fisette, 1990:11); se trata - como se puede ver - de un segundo estado del signo. Apoyado pues en el interpretante, el pasaje de un signo a otro significa una ganancia, un plus de valor, 
que no es otra cosa más que un mayor grado de semiotización (insistamos: no hay, para Peirce, instancia no semiótica). De este modo, la interpretancia queda definida como la traducción de un signo en otro distinto, ya sea en el marco de un mismo código (i.e. la traducción de un texto de un idioma a otro) o atravesando sus límites (i.e. la transposición de una pintura en una obra literaria, la de una obra literaria al cine).

\section{EL DISPOSITIVO Y LA DIMENSIÓN MATERIAL DEL SENTIDO}

El cambio de dispositivo que implica la transposición también produce un sentido específico. Ahora bien, ¿qué es un dispositivo? Pregunta que ya ha ocasionado gran cantidad de páginas. Observemos el fenómeno en su amplitud. La relación del individuo con el libro o con la imagen cinematográfica se encuentra socialmente sobredeterminada; los medios y técnicas de producción de la materia semántica, los soportes empleados para hacerla circular, los modos de su circulación, los lugares dispuestos para su accesibilidad (cf. Aumont, 1992:143) son sólo algunas de las determinaciones comprometidas necesariamente en la constitución de un universo específico de sentido, determinaciones que - es evidente - mutan con el pasaje transpositivo.

Traversa (2001), analizando los medios, piensa al dispositivo como una entidad encargada de gestionar el contacto entre el individuo y las múltiples configuraciones sígnicas de la discursividad social (i.e. el libro y su lector, la imagen cinematográfica y su espectador etc.), a partir de la activación de un condensado de medios y técnicas, y una determinada configuración institucional para su aplicación. Considerar el dispositivo en estos términos no es otra cosa más que pensar el carácter formante de la dimensión material en la producción social de sentido ${ }^{3}$. Formante decimos, ya que resulta evidente - aunque, tal vez por ello, muchas veces ignorado - que es la materialidad la que establece un modo de registro específico (i.e. visual, auditivo), un combinado de condiciones de acceso y, por tanto, integra, como presupuesto, las condiciones de producción discursivas; la variabilidad del registro, su mayor o menor grado de complejidad, exige asimismo un diverso compromiso de elementos cognitivos y conductales (i.e. audiovisual en el caso del cine, visual ¿y táctil? en el del libro).

En otros términos, se trata de considerar una acumulación y determinación recíproca de técnicas que nunca - insistimos - permanecen ajenas a la producción de sentido: unas técnicas biológicas primeras que trabajan sobre la materia (i.e. la escritura, la voz, cierta disposición corporal) necesitan de otras técnicas o mediaciones socialmente reguladas (i.e. el libro, la radio, el cine) que posibilitan y modulan, en cada caso, su despliegue (i.e. reglas de producción de un libro, de un film) y nuestra toma de contacto con ellas (i.e. el contacto no lo establecemos con la escritura directamente, sino con un libro o un monitor). Es obvio que esta concepción del dispositivo no agota la indagación sobre los procesos de producción de sentido de un fenómeno discursivo (la sola consideración de la técnica, por ejemplo la cinematográfica, descuida que esta puede aplicarse a fines diversos, como el de ser un elemento de medición de velocidades); sin embargo, las consecuencias del análisis - y esto es lo importante - no serán las mismas si se decide comenzar por el contenido semántico o por la sustancia material y las técnicas que la marcan. 


\section{GÉNEROS, RELECTURAS Y ESTRATEGIAS}

En una transposición, lo que constituye objeto de análisis semiológico es el estudio de los desvíos sobre el fondo del isomorfismo. Una primera cuestión a considerar es el pasaje no ya de una obra particular, sino de todo un género, o de un sistema de géneros, de un medio a otro. Caso central: el traslado de los géneros literarios a los medios masivos (trabajado por Steimberg, 1998:115-136). La inestabilidad de los géneros literarios (y de la misma noción de género) y la proliferación de los medios masivos complejizaron, por cierto, el fenómeno y dividieron - como señalamos al principio - las posiciones sobre su valoración. Mencionemos apenas algunos detalles básicos del asunto. En la instancia de recepción, los géneros funcionan, en un momento dado sucede así con todo fenómeno de la discursividad social -, como una categoría clasificatoria metatextual (creada, si tomamos el caso del cine, por alguna zona de la industria), sustentada en dos tipos de relaciones: de repetición (de elementos) y de inclusión (de los mismos dentro de una clase, borrando sus diferencias). En el caso del cine, como en el de los otros medios de masas, la previsibilidad genérica refrendada en un contrato paratextual (i.e. La guerra de las galaxias es promocionado como un film de ciencia ficción ${ }^{4}$ ) es un aspecto importante del dispositivo en todo lo que concierne a la circulación social de sus productos. Para la industria cinematográfica, los géneros son conceptos ordenadores y valorizadores del film; para el espectador, son configuradores de una memoria de su gusto: ante la amplitud y fragmentación del campo de la producción cinematográfica, su conocimiento de los géneros (casi siempre ignorada por él mismo) le otorga cierta seguridad para conseguir su goce (Traversa, 1984).

En lo que se refiere a la transposición de una obra en particular, además de los géneros de pertenencia, hay otras variables para explicar la resignificación: las que emanan de un presente y cultura específicas y que, según Steimberg (1998), se pueden presentar a través de dos vías. Una primera que, respetando los motivos temáticos principales o la normatividad de un género, privilegiaría la accesibilidad de la lectura; es una permanencia del relato, de lo narrativo tal cual se lo conoce, en la transposición, a la que se llega, entre otras estrategias, jerarquizando sus funciones nucleares y la importancia del desenlace (i.e. la versión de Bruno Barreto de Dona Flor e seus dois maridos). Es asimismo posible, segunda vía, que en la transposición se haga una exploración sobre algún nivel específico del texto fuente, señalando, sea por una estrategia deliberada de quien relee, sea por la orientación de una industria o un medio, sea por azar, alguna zona que no había entrado en la lectura social estereotipada del mismo, produciendo un efecto de desconfirmación (i.e. consideremos aquí una relectura centrada en la exploración de los fenómenos psicológicos que guían al personaje central, la que realizan Scorsese y su guionista, Wesley Strick en Cabo de miedo, segunda adaptación al cine de The executioners, novela de John MacDonald ${ }^{5}$. Algunas estrategias para lograr tal efecto: omisiones (secuencias, personajes etc.), exageraciones, atenuaciones, puesta en evidencia de ciertos clichés. En pocas palabras, cabe afirmar que el primero de los caminos acentúa los mecanismos verosimilizadores del texto transpuesto; el segundo, en cambio, los quebranta. 


\section{CONCLUSIONES}

A modo de conclusión, sólo reiteraremos que la transposición es, como todo fenómeno de intertextualidad y reformulación, un rasgo clave de nuestra cultura. Su estudio a fondo requiere no olvidar que los cambios de sentido de la materia semántica no sólo son adjudicables a determinaciones individuales, culturales o regionales, sino que también deben ser explicados por el cambio significante en la dimensión material, en los lenguajes y en los géneros.

\section{Notas}

\footnotetext{
${ }^{1}$ La versión (o remake en el caso del cine) es el más acá de la transposición, ya que no hay cambio de soporte y la obra nace bajo las mismas operaciones constitutivas.

${ }^{2}$ A lo sumo - claro está - ese funcionamiento podrá ser mostrado. Tampoco se nos escapa lo tramposo del ejemplo, dado que entre lengua y semáforo existe, ante todo, una diferencia de complejidad.

${ }^{3}$ La mayoría de estas consideraciones sobre el dispositivo, como las que siguen, son deudoras de las exposiciones del Dr. Oscar Traversa realizadas durante el seminario "Medios y técnicas: cuestiones acerca de la materialidad del sentido", dictado en el marco de la Maestría en Análisis del Discurso de la U.B.A.

${ }^{4}$ Sabemos que simplificamos en extremo este problema dejando de lado otra cuestión central en la producción cultural de nuestra época: la hibridación genérica. Por ejemplo, para una base de datos cinmatográfica planetaria como lo es IMDB, el género de La guerra de las galaxias es: “acción/aventura/fantasía/ciencia ficción”.

${ }^{5}$ Cape Fear de Scorsese es de 1991, y es la remake del film homónimo de 1962, dirigido por Lee Thompson con guión de James Webb.
}

\section{REFERÊNCIAS BIBLIOGRÁFICAS}

AUMONT, Jacques. La imagen. Barcelona: Paidós, 1992.

BENVENISTE, Émile. "Semiología de la lengua". In: lingüística general II. México: Siglo XXI, 2002 (1974).

Problemas de

FISETTE, Jacques. Introduction à la sémiotique de C. S. Peirce. Montreal: XYZ, 1990.

METZ, Christian. "Le film de fiction et son espectateur (Etude métapsychologique)". In : AA.VV. Psycanalyse et cinéma. Comunication $\mathrm{n}^{\circ} 23,1975$.

STEIMBERG, Oscar. Semiótica de los medios masivos. El pasaje a los medios de los géneros populares. Buenos Aires: Atuel, 1998.

TRAVERSA, Oscar. Cine: el significante negado. Buenos Aires: Hachette, 1984. .Carmen, la de las transposiciones", La Plata, Actas del 1er. Congreso Nacional de Semiótica, 1986.

. "Aproximaciones a la noción de dispositivo". In: Signo y Seña $n^{\circ} 12,233-$

247, 2001. 
Como citar este artigo:

BERMÚDEZ, Nicolás Diego. Aproximaciones al fenómeno de la transposición semiótica: lenguajes, dispositivos y géneros. Estudos Semióticos. [online] Disponível na Internet via WWW.URL: http://www.fflch.usp.br/dl/semiotica/es. Editor Peter Dietrich. Número 4, São Paulo, 2008.

Acesso em "dia/mês/ano". 